LA W RENCE LIVERMORE NATIONAL LABORATORY
3D WAVE PROPAGATION AND SITE EFFECTS IN THE HUMBOLDT BAY AREA USING STRONG GROUND MOTION RECORDS FROM THE M6.5 2010 FERNDALE EARTHQUAKE

A. Pitarka

January 30, 2013 
This document was prepared as an account of work sponsored by an agency of the United States government. Neither the United States government nor Lawrence Livermore National Security, LLC, nor any of their employees makes any warranty, expressed or implied, or assumes any legal liability or responsibility for the accuracy, completeness, or usefulness of any information, apparatus, product, or process disclosed, or represents that its use would not infringe privately owned rights. Reference herein to any specific commercial product, process, or service by trade name, trademark, manufacturer, or otherwise does not necessarily constitute or imply its endorsement, recommendation, or favoring by the United States government or Lawrence Livermore National Security, LLC. The views and opinions of authors expressed herein do not necessarily state or reflect those of the United States government or Lawrence Livermore National Security, LLC, and shall not be used for advertising or product endorsement purposes.

This work performed under the auspices of the U.S. Department of Energy by Lawrence Livermore National Laboratory under Contract DE-AC52-07NA27344. 


\title{
3D WAVE PROPAGATION AND SITE EFFECTS IN THE HUMBOLDT BAY AREA USING STRONG GROUND MOTION RECORDS FROM THE M6.5 2010 FERNDALE EARTHQUAKE.
}

Arben Pitarka

Lawrence Livermore National Laboratory, Livermore

\begin{abstract}
In this study we simulate and analyze strong ground motion waveform data recorded in the Humboldt Bay and Eureka areas during the M6.5 Ferndale earthquake of January 2010. The scope of the presented work was two-fold. First, we investigated the main aspects of seismic wave generation and propagation, including kinematic rupture process and 3D wave propagation scattering. Our goal is to analyze their potential effects on seismic motion recorded at free field stations across Humboldt Bay and Eureka, California, and test the performance of a standard broadband strong ground motion simulation technique. Second, we evaluated the implication of the non-linear response of shallow sediments on ground motion recorded at the Humboldt Bay geotechnical array. Using synthetic and recorded data we compared the performance of numerical and empirical techniques in simulating local non-linear site response. Our study provides insight into the composition of the wave field during the earthquake and an improved understanding of how the strong ground motion is affected by the 3D structure and non-linear response of shallow sedimentary layers in the Humboldt Bay.
\end{abstract}

\section{Introduction}

The M6.5 Ferndale earthquake occurred north of the Mendocino Triple junction, in a region with complex structure caused by subducting plates. The epicenter of this strike-slip earthquake is located at a depth of about $29 \mathrm{~km}$, and the fault plane is within the subducting Gorda plate. The damage to buildings was concentrated along the coast from Ferndale to Eureka, California. Areas located on deep estuary and river deposits had higher damage compared with areas located on shallower soils and rock (Storesund, 2010). The earthquake was well recorded by over 20 free-field strong ground motions stations located along the coast in Ferndale and Eureka and more than 60 instruments installed on several bridges and buildings. Of particular interest are records from the geotechnical array installed near the Humboldt Bay bridges.

In Figure 1 we compare the recorded peak ground acceleration and peak ground velocity with ground motions predicted by NGA ground motion prediction equations for crustal earthquakes (Abrahamson et al., 2008) and a ground motion model for intraslab earthquakes (Zhao et al. 2006). The comparison displays two distinct features of the recorded motion. First, the recorded motion has a less gradual attenuation with distance than the ground motion prediction equations. This could be explained by the fact that the earthquake was a mantle earthquake, not a shallow crustal earthquake of the kind modeled 
by the NGA ground motion prediction equations. Its location below the oceanic Moho in a region that is expected to have a low velocity gradient, apparently resulted in rapid attenuation, because there is no strong velocity gradient such as the Moho to cause the gradual attenuation of ground motions which is typical for crustal earthquakes (e.g. Somerville et al.,1984). Second, the peak ground acceleration and velocity recorded along the coast, at fault distances between $30 \mathrm{~km}$ and $40 \mathrm{~km}$, is much higher than the average horizontal peak ground motion predicted by equations for crustal strike-slip earthquakes. The largest recorded ground acceleration and velocity were about $44 \% \mathrm{~g}$ and $47 \mathrm{~cm} / \mathrm{s}$, respectively, at Ferndale, about $43 \mathrm{~km}$ east of the epicenter. In contrast, the Zhao et al. (2006) equation, developed for earthquakes within subducting slabs, provides a better fit to both peak ground motion and attenuation rate with distance.

The relatively large ground motion observed at sites along the coast could also be caused by basin and local site effects. We use a series of broad-band numerical simulations to investigate the implication of the three-dimensional underground structure and local site effects on recorded strong ground motion. Our simulations yielded ground motion time histories that could also be used for engineering purposes.

\section{Strong Motion Records}

We used ground motion waveform data recorded by free-field strong-motion stations of the California Geological Survey (CGS), U.S. Geological Survey, and the geotechnical array, posted on the Center of Engineering Strong Motion Data web site. The corrected three component accelerograms were downloaded from the website of the CGS strong motion center (http://www.strongmotioncenter.org). This data set provides an excellent resource for analyzing wave propagation and local site effects. In addition to free-field stations the earthquake was very well recorded by more than 60 instruments installed on buildings and bridges. The location of strong motion sites that were used in our study is shown in Figure 2. A photo of the Humboldt Bay channel bridges is shown in Figure 3. The geotechnical array is located about $300 \mathrm{~m}$ north-west of the west abutment of the Middle Channel Bridge

\section{Three-Dimensional Velocity Model}

Ferndale area is underlied by thick sedimentary layers. The basin structure is shaped by active faults, including the Little Salmon fault that runs across the basin. We used geotechnical data (Clarke, 1992) and available geophysical and geological profiles to develop the extension of the three-dimensional (3D) velocity model of the Eel River basin developed by the URS group (Graves, 1994). The URS velocity model was originally developed to study ground motion and rupture process of the 1992 Cape Mendocino earthquake (Graves, 1994). Our 3D model extends to the north, and includes the Humboldt Bay and Eureka areas. The map of the basin depth is shown in Figure 4. The offshore basin structure is not well resolved by the available data. Therefore we assumed a rather flat basin geometry that extends to the west of the coastal line and used GIL7, a 1D crustal velocity model (Dreger, 2011, personal communication), as background. The fault plane 
cuts through two crustal layers with a strong velocity contrast. The basin sediments are represented by two layers with a minimum shear-wave velocity of $620 \mathrm{~m} / \mathrm{s}$. A map view and a vertical cross-section of the 3D velocity model are shown in Figure 5 . The finitedifference simulations were performed using a $200 \mathrm{~m}$ grid spacing that allows for accurate computation of the wave field up to $0.8 \mathrm{~Hz}$.

\section{Kinematic Slip Model of the 2010 Ferndale Earthquake}

Analysis of the earthquake indicates that slip occurred on a near-vertical, left-lateral fault oriented about N47E. Large strike-slip earthquakes like this one are common in the interior of the Gorda plate. The hypocenter was located at a depth of $29 \mathrm{~km}$, but the accuracy is relatively poor owing to the earthquake occurring about $40 \mathrm{~km}$ offshore and 36 $\mathrm{km}$ from the nearest seismic station. A preliminary inversion of long period ground motion displacement by the UC Berkeley Seismological Laboratory (Dreger, 2010, personal communication) estimated a fault length of about $25 \mathrm{~km}$, and suggests that the fault rupture proceeded unilaterally to the southwest. The estimated peak slip was 2.4 meters.

We started the investigation of the source process by simulating long-period $(0.1-0.8 \mathrm{~Hz})$ ground motion velocity at 11 stations located along the coast. In our simulation we used 3D Green's functions computed with a finite-difference method (Pitarka, 1999). We found that the original kinematic slip model does a poor job at explaining the recorded motion. Based on trial and error analysis we produced a kinematic rupture model that explains the overall characteristics of recorded ground motion on a broad frequency range. The slip model is shown in Figure 6. The fault geometry is the same and the mechanism is similar to UC Berkeley's model. We use a strike angle of 230 degrees, dip angle of 86 degrees, rake angle of 11 degrees, maximum rupture velocity of $2.8 \mathrm{~km} / \mathrm{s}$, and a maximum rise time of $1.7 \mathrm{~s}$. The local slip is represented by two time-windows with a $0.3 \mathrm{~s}$ overlaping. The subfault dimensions are 1 by $1 \mathrm{~km}$. The details of the rupture kinematics are still not well resolved due to poor station distribution and limited knowledge of underground structure in the source region. Our kinematic model suggests that the rupture was bilateral, and a zone of large slip was located north of hypocenter, with a maximum slip of $1.2 \mathrm{~m}$.

\section{Broad-Band Ground Motion Modeling}

We used the broad-band simulation procedure of Graves and Pitarka (2010) to simulate ground motion at 11 stations shown in Figure 2. The simulation procedure is a hybrid technique that computes the low-frequency and high-frequency parts of the ground motion separately, and then combines the two to produce a broad-band time history. At frequencies below $0.8 \mathrm{~Hz}$, the methodology is deterministic. It uses a theoretically rigorous representation of fault rupture kinematics and wave propagation, and attempts to reproduce recorded ground-motion waveforms and amplitudes. At frequencies above 0.8 $\mathrm{Hz}$, it uses a stochastic representation of source radiation, which is combined with a simplified theoretical representation of wave propagation scattering effects (Pitarka et al.,2000). The simulation uses site corrections proposed by Campbell and Bozorgnia (2008) 
based on Vs30.

Being a deep intra-slab earthquake, the 2010 Ferndale earthquake is expected to have a relatively high stress drop. Therefor the stress drop factor (Graves and Pitarka, 2010) we used in the simulation of the high frequency part of ground motion is about $25 \%$ higher than the one we typically use in simulations of shallow crustal earthquakes on strike-slip faults. The comparison between recorded and simulated time histories of acceleration and velocity, and acceleration response spectra are shown in Figures 7 and Figure 8, respectively. The primarily bilateral fault rupture that initiated at the center of the fault produced strong rupture directivity effects toward the northeast and southwest. Due to their relative location with respect to the fault most of the sites are affected by the rupture directivity toward the north-east. The large velocity pulse observed on the N-S component at stations north-east of epicenter is well reproduced by the simulation. This pulse is controlled by the rupture directivity to the north-east. The large pulse observed on the E-W component at sites south-east of epicenter is not well reproduced. This could indicate that the second asperity located south of the rupture initiation area has a larger slip and probably slightly different focal mechanism.

We compute the model bias and standard error for 5\% damped spectral acceleration over a suite of periods from 0.05 to $8 \mathrm{~s}$ for the simulation using 11 sites. The results are displayed in Figure 9 for the fault-parallel, fault-normal, and average horizontal (geometric mean) components. The model bias is near zero for all components across the entire bandwidth indicating that, on average, the simulation is accurately reproducing the main characteristics of the observed ground motions. The largest standard error for these comparisons is about 0.2 natural log units for periods less than about $0.8 \mathrm{~s}$. For periods longer than $0.8 \mathrm{~s}$, the standard error increases to about 0.4 natural log units. The larger standard error at longer periods is mainly due to deficiencies in the rupture model, and inaccuracies in the 3D velocity model.

Figure 10 compares simulated and recorded peak ground acceleration, and simulated and recorded maximum ground acceleration. Ground motion prediction equations for a strikeslip earthquake of the same size are also shown. The maximum ground acceleration is calculated as the largest peak value of the two orthogonal component of motion. Figure 11 shows similar comparisons, but for velocity. It is noticeable that the simulation does a better job at predicting the variability in the peak ground acceleration than it does for the peak ground velocity. We explain this by the smooth geometry of the basin model and assumed planar fault geometry which might decrease the spatial variability of long period ground motion, mainly due to reduced wave scattering and simple radiation pattern. The two sites that have the lowest recorded peak ground motion velocity are NP1584 and NP1580. They are the only sites that are located on firm soil conditions, outside the basin.

\section{Nonlinear Soil Response Analysis}

The ground motion from the 2010 Ferndale earthquake recorded at the Humboldt Bay geotechnical array provides an opportunity for testing the efficiency of current nonlinear 
techniques for predicting soil response under moderate shaking. The array is located about $300 \mathrm{~m}$ north-west of the west abutment of the Middle Channel Bridge (see Figure 3). It contains four borehole instruments installed at the free surface and at depths of $19 \mathrm{~m}, 33 \mathrm{~m}$, $56 \mathrm{~m}$, and $136 \mathrm{~m}$. The corrected three component accelerograms were downloaded from the website of the CGS strong motion center (http://www.strongmotioncenter.org).

We used the computer program NOAH_SH based on the nonlinear soil response technique of Bonilla et al. (2005) to analyze the horizontal soil response recorded by the borehole instruments. NOAH_SH uses the staggered-grid finite-difference method and Iwan's (1967) nonlinear soil model. The technique operates in the time domain by tracking the earthquake load through stress-strain space. It allows the direct use of G/Gmax laboratory data that can be assigned to each layer. Typically it uses the Masing rule for unloading and re-loading. Reviews of the methodology can be found in the work of Joyner and Chen (1975) and Bardet (2001). Recent applications of the NOAH_SH computer program as well as comparisons with other traditional methods such as the equivalent linear method are shown in the study of Hartzell et al. (2004). Nonlinear finite-difference techniques have several advantages over the classical equivalent linear method. First, with a finite difference method one can easily obtain the strain from the node displacement gradient that is then introduced into the constitutive equation to compute the stress. Second, the constant damping, independent of frequency, used in the equivalent linear methods causes the over-attenuation of high frequencies, especially at high level of strain. This effect is easily avoided in the finite difference methods.

In our site response analysis we used the Peninsular Range (PR) modulus reduction, $G / G \max$, and damping curves as a function of shear strain for cohesionless soil developed by Silva et al. $(1997,1999)$. We used the Vucetic and Dobry (1991) curves for a plasticity index of 30 for the top clay layers. The PR curves are a subset of the EPRI (1993) curves developed by modeling recorded motion. We adopted them for soils below $7 \mathrm{~m}$. The 1D velocity model used in the non-linear simulations is shown in Figure 12. It is based on borehole shear-wave speeds provided by Caltrans. The shear wave velocity increases from about $180 \mathrm{~m} / \mathrm{sec}$ at the free surface to $630 \mathrm{~m} / \mathrm{s}$ in hard rock at $220 \mathrm{~m}$ depth.

Figure 13 compares time histories and amplitude spectra of recorded and computed ground motion acceleration at the geotechnical array. The recorded E-W component of acceleration at a depth of $136 \mathrm{~m}$ was used as input motion to compute the non-linear response of the shallow sedimentary layers. The synthetic accelerograms compare well with the recorded accelerograms at all depths. Similarly Figure 14 compares the recorded and simulated time histories of acceleration assuming an equivalent linear soil response.

The performance of the equivalent linear technique is similar to the fully non-linear technique. Although this is an encouraging result it should be mentioned that the input ground motion acceleration is of moderate intensity. The equivalent linear simulation does a poor job in matching the recorded motion at frequencies $1-3 \mathrm{~Hz}$. This is also clearly seen in the comparison of the acceleration time histories at all depths. As a reference we also performed simulations using a purely elastic response of soils. The comparison of the acceleration time histories and corresponding amplitude spectra are shown in Figure 15. 
These results clearly show that the non-linear response of soils suppresses much of the high frequency energy as the waves propagate through the soil column.

One key aspect of the broad-band simulation methodology used here is the correction for site effects. We apply empirical site corrections factors based on Vs30(Campbell and Bozorgnia,2008) in order to take into account local site effects in both linear and non-linear regimes. We tested the performance of the empirical site correction technique at capturing non-linear site effects at the geotechnical array. Synthetic ground motion at the free surface was computed using the fully non-linear site response and the empirical site correction using Vs30. The E-W and N-S components of broad-band time histories computed at the base level of the array were used as input motions. The comparison between both approaches is shown in Figure 16. The empirical site correction produces slightly higher amplitudes in the first cycles of the acceleration time history. Its overall performance is satisfactory in the considered frequency range of $0.1-10 \mathrm{~Hz}$.

\section{Final Remarks and Conclusions}

Intra slab earthquakes similar to the M6.5 Ferndale 2010, California earthquake can generate larger ground motion than shallow crustal earthquakes of same magnitude. Therefore their study is very important for strong ground motion prediction and seismic hazard assessment. To our knowledge this is the first attempt to apply a broad-band ground motion simulation method, originally validated for crustal earthquakes, to an intra slab earthquake in the US.

Slab earthquakes occur in areas of large velocity contrast and increased regional stress. Such conditions have a significant impact on fault geometry, rupture dynamics and seismic energy release. The 2010 Ferndale earthquake occurred offshore in a very complex tectonic environment near Mendocino Triple junction. The unknown structural complexity and poor azimuthal strong motion station coverage due to offshore fault location made very difficult the development of a rupture model. In simulating strong ground motion from the 2010 Ferndale earthquake we relied on a kinematic rupture model of the earthquake that was constrained by aftershock locations and inversion of regional waveform data, both purely resolved by the incomplete stations coverage (Dreger, 2011, personal communication).

The hybrid simulation method of Graves and Pitarka (2010) performed relatively well in reproducing some of the characteristics of recorded ground motion at stations in the Ferndale region. The only parameter that needed an adjustment was the stress drop factor. We used a stress drop factor that is $25 \%$ higher than the one we commonly use in simulations of strike-slip faults for crustal earthquakes. This suggests that the stress drop of the 2010 Ferndale earthquake was relatively high compared to shallow strike slip earthquakes. Our finding is in agreement with observations made for intra-slab earthquakes of similar type (e.g. Asano et al., 2003; Chung and Kanamori, 1980). Our 3D modeling of long-period ground motion recorded at sites along the coast in the Ferndale region suggests that the fault rupture was bilateral, and that rupture directivity caused the 
pulse-like initial phase mostly observed on the N-S component at sites in the Humboldt Bay.

Basin induced waves amplified the ground motion, and generated secondary waves, that are observed at stations located in the deepest part of the basin. The 3D/1D wave propagation effects are illustrated in Figure 17. In this figure we compare long period velocity seismograms $(0.02-0.8 \mathrm{~Hz})$ computed with our 3D velocity model and 1D equivalent basin model. 3D synthetics at stations NP1746, NP1023 and 89973, located in the deepest part of the basin, contain basin-induced waves that are manifested by a large pulse after the direct wave. The effective amplification due to the basin sedimentary layers in the frequency range of $0.1-0.8 \mathrm{~Hz}$ is estimated to be about 1.6. It was measured as the maximum peak amplitude ratio between 3D and 1D synthetics at non-basin sites, NP1580 and NP1584. We concluded that basin sediments and local site effects contributed to ground motion amplification at soils sites along the coast.

1D wave propagation analysis at the geotechnical array, using a fully non-linear numerical technique (Bonilla et al., 2005), show that the seismic response of soft sedimentary layers in the Humboldt Bay can be well modeled by a fully non-linear technique. Our 1D non-linear site response analysis using strong motion data recorded at the geotechnical array suggests that for moderate input ground motion with peak acceleration of about 0.7g, the fully-non-linear (Bonilla et al., 2005) and an equivalent linear method used in this study give similar results. Our investigation of the performance of the empirical site correction factors based on Vs30 (Campbell and Bozorgnia, 2008) used in association with a broad-band ground motion simulation methodology (Graves and Pitarka, 2010) shows that site correction factors based on Vs30 perform well in representing the non-linear local site response at the Humboldt Bay geotechnical array. Broad-band synthetic accelerograms computed with the technique tested here can be used to further investigate the seismic response of soils and bridges in the Humboldt Bay area for different intra-slab rupture scenarios.

\section{Acknowledgment}

We thank Anthony Shakal and Jousef Bozorgnia for their comments and suggestions, and Fabian Bonilla for providing his computer programs, NOAH_SH and TREMORN25, that we used to compute the 1D non-linear and equivalent linear response of soils.

\section{References}

Abrahamson, N.A., G.M. Atkinson, D.M. Boore, Y. Bozorgnia, K.C. Campbell, B. Chiou, I. M. Idriss, W.J. Silva, and R.R. Youngs (2008). Comparisons of the NGA Ground-Motion Relations. Earthquake Spectra 24, 45-66.

Asano, K., T. Iwata, and K. Irikura (2003). Source characteristics of shallow intraslab earthquakes derived from strong-motion simulations. Earth Planets Space, 55, e5-e8. 
Bardet, J.P. and T. Tobita (2001). NERA a computer program for Nonlinear Earthquake site Response Analyses of Layered Soil Deposits, Department of Civil Engineering, University of Southern California, $46 \mathrm{pp}$.

Bonilla, L. F. (2000). Computation of linear and nonlinear site response for near field ground motion, Ph.D. Thesis, University of California, Santa Barbara.

Bonilla, L., F., R. Archuleta, and D. Lavallee (2005). Hysteretic and dilatant behavior of cohesionless soils and their effects on nonlinear site response: field data, observations and modeling, Bull. Seism. Soc. Am., 95, 2373-2395.

Chung, W.-Y. and H. Kanamori, Variation of seismic source parameters and stress drops within a descending slab and its implications in plate mechanics, Phys. Earth Planet. Inter., 23, 134-159, 1980.

Clarke, S. H. (1992). Geology of the Eel River basin and adjacent region: Implications for late Cenozoic tectonics of the southern Cascadia Subduction Zone and Mendocino Triple Junction, AAPG Bulletin, 76, 199-224.

Graves R. W. (1994). Rupture history and strong ground motion modeling of the 1992 Cape Mendocino earthquake. Report to USGS, award \# 1434-93-G-0237.

Graves, R. W. and A. Pitarka (2010). Broadband ground-motion simulation using a hybrid approach. Bull. Seism. Soc. Am., 100, 5A, 2095-2123.

Hartzell, S.H., L.F. Bonilla, and R.A. Williams (2004). Prediction of nonlinear soil effects, Bull. Seism. Soc. Am., 94, 1609-1629.

Huang, N. E., Shen, Z., Long, S. R., Wu, M. C., Shih, E. H., Zheng, Q., Tung, C. C. \& Liu, H. H. (1998). The empirical mode decomposition method and the Hilbert spectrum for nonstationary time series analysis. Proc. R. Soc. Lond. A454, 903-995.

Iwan, W.D. (1967). On a class of models for the yielding behavior of continuous and composite systems, J. of App. Mech., 34, 612-617.

Joyner, W., and A.T. Chen (1975). Calculation of nonlinear ground response in earthquakes, Bull. Seism. Soc. Am., 65, 1315-1336.

Pitarka, A. (1999). 3D elastic finite-difference modeling of seismic motion using staggered grids with nonuniform spacing. Bull. Seism. Soc. Am. 89, 54-68.

Pitarka, A., P.G. Somerville, Y. Fukushima, T. Uetake, K.Irikura (2000). Simulation of nearfault ground motion using hybrid Green's functions, Bull. Seism. Soc. Am. 90, 566-586.

Silva, W., N. Abrahamson, G. Toro, and C. Costantino (1997). Description and validation of the stochastic ground motion model, Report submitted to Brookhaven National Laboratory, Associated Universities, Inc., Upton, New York 11973, Contract No. 770573.

Silva, W., Li,S., B. Darragh, and N. Gregor (1999). Surface geology based strong motion amplification factors for the San Francisco Bay and Los Angeles areas. Pearl Report to PG\&E/CEC/Caltrans. (http://www.pacificengineering.org).

Somerville, P.G., N.F. Smith, and R.W. Graves (1994). The effect of critical Moho reflections on the attenuation of strong motion from the 1989 Loma Prieta earthquake, in "The Loma Prieta, California, Earthquake of October 17, 1989 - Strong Ground Motion," U.S. Geological Survey Professional Paper 1551-A, A67-A75.

Storesund, R., L. Dengler, S. Mahin, B.D. Collins, M. Hanshaw, F. Turner, K. Welsh (2010). M6.5 Earthquake Offshore Northern California January 9,2010. GEER Field Reconnaissance Summary.

Vucetic, M., and R. Dobry (1991). Effect of soil plasticity on cyclic response, J. Geotech. Eng. ASCE 117, 89-107. 
Zhao J.X., Zhang J., Asano A., Ohno Y., Oouchi T., Takahashi T., Ogawa H., Irikura K., Thio, H.K., Somerville P.G., Fukushima Y. (2006). Attenuation relations of strong ground motion in Japan using site classification based on predominant period. Bull. Seism. Soc. Am. 96,914-925.

Yang,Z, J. Bielak, J. P. Conte, A. Elgamal (2003). Treatment of seismic input and boundary conditions in nonlinear seismic analysis of a bridge ground system. $16^{\text {th }}$ ASCE Engineering Mechanics Conference, July 16-18, University of Washington, Seattle.
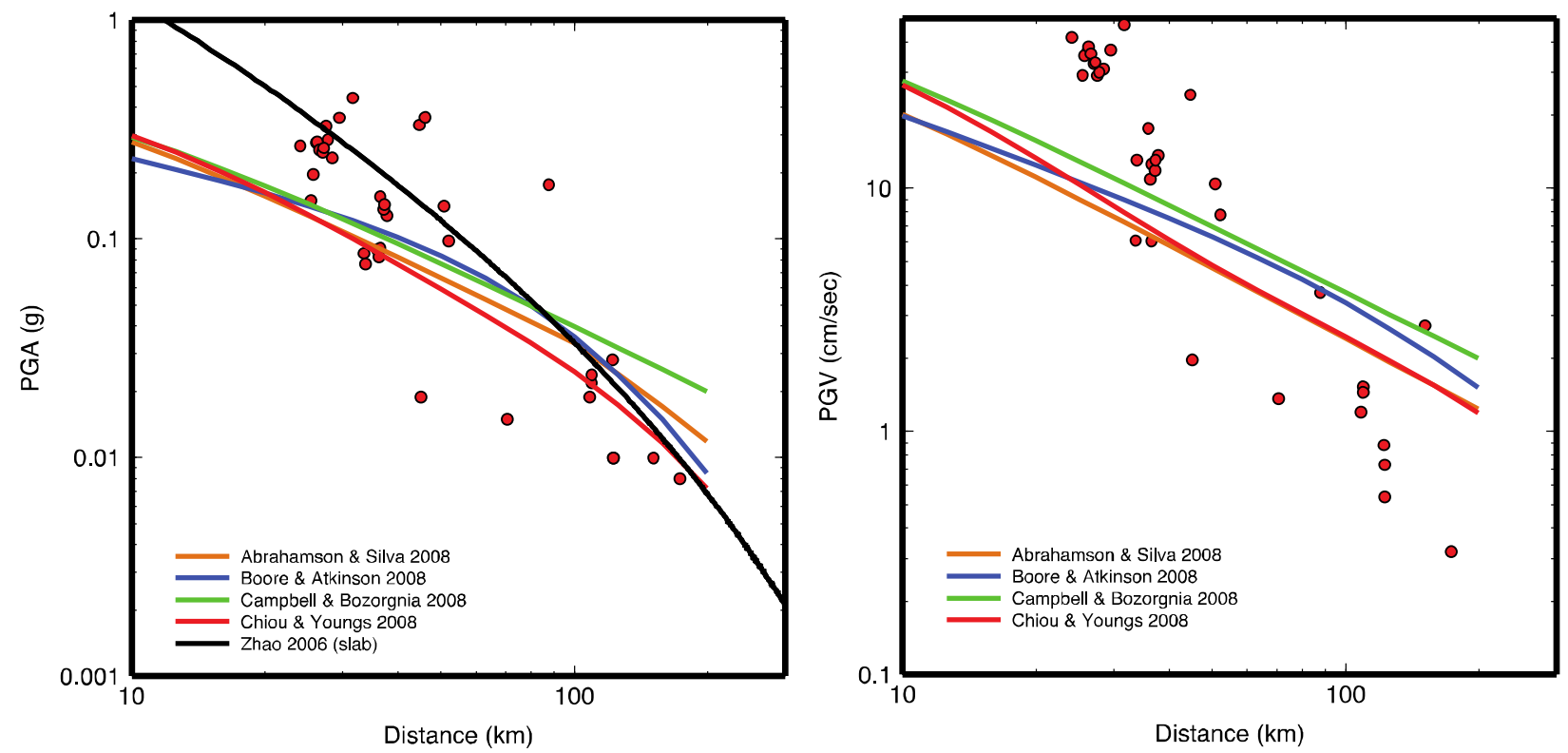

Figure 1. Comparison of recorded peak acceleration (left panel) and peak velocity (right panel) from the 2010 M6.5 Ferndale earthquake with predictions of the average horizontal motion using different ground motion equations.
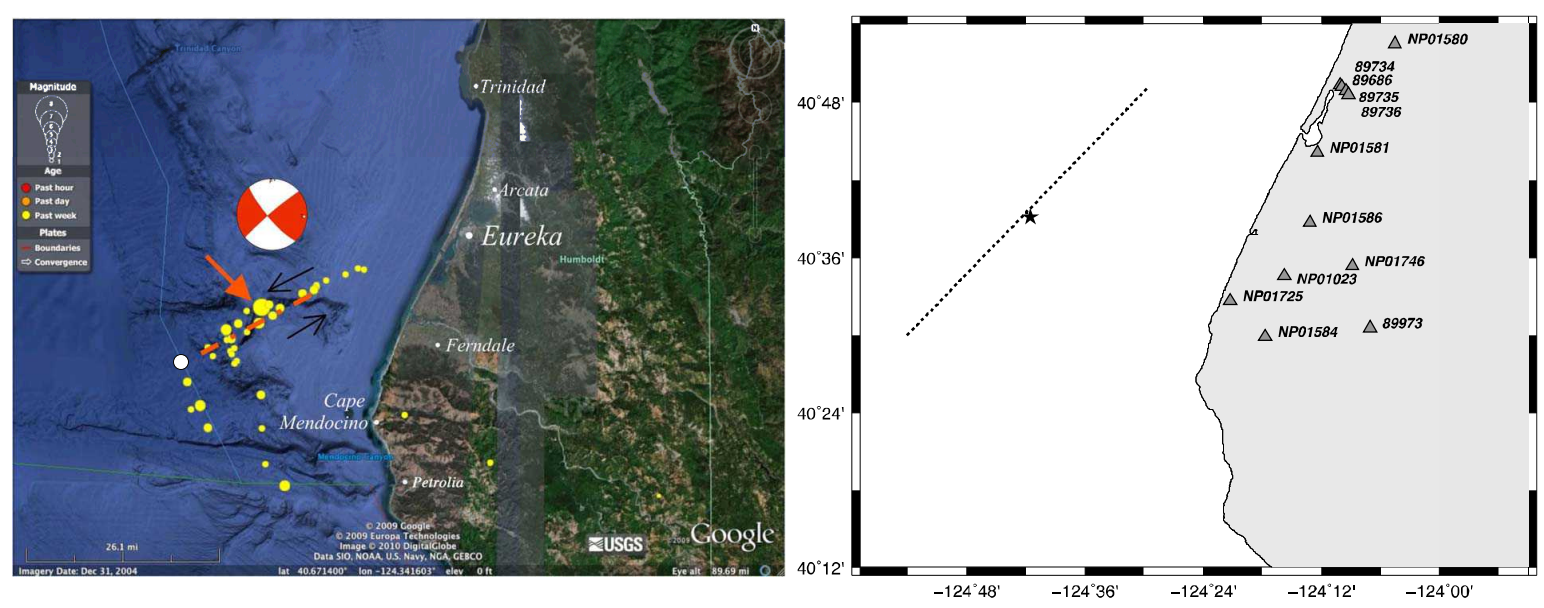

Figure 2. Left: Map showing main aftershocks location. Arrow indicates the location of the epicenter. Right: Map of the study area showing the stations location (triangles), ocean-bottom fault projection (dotted line), and epicenter location (star). 


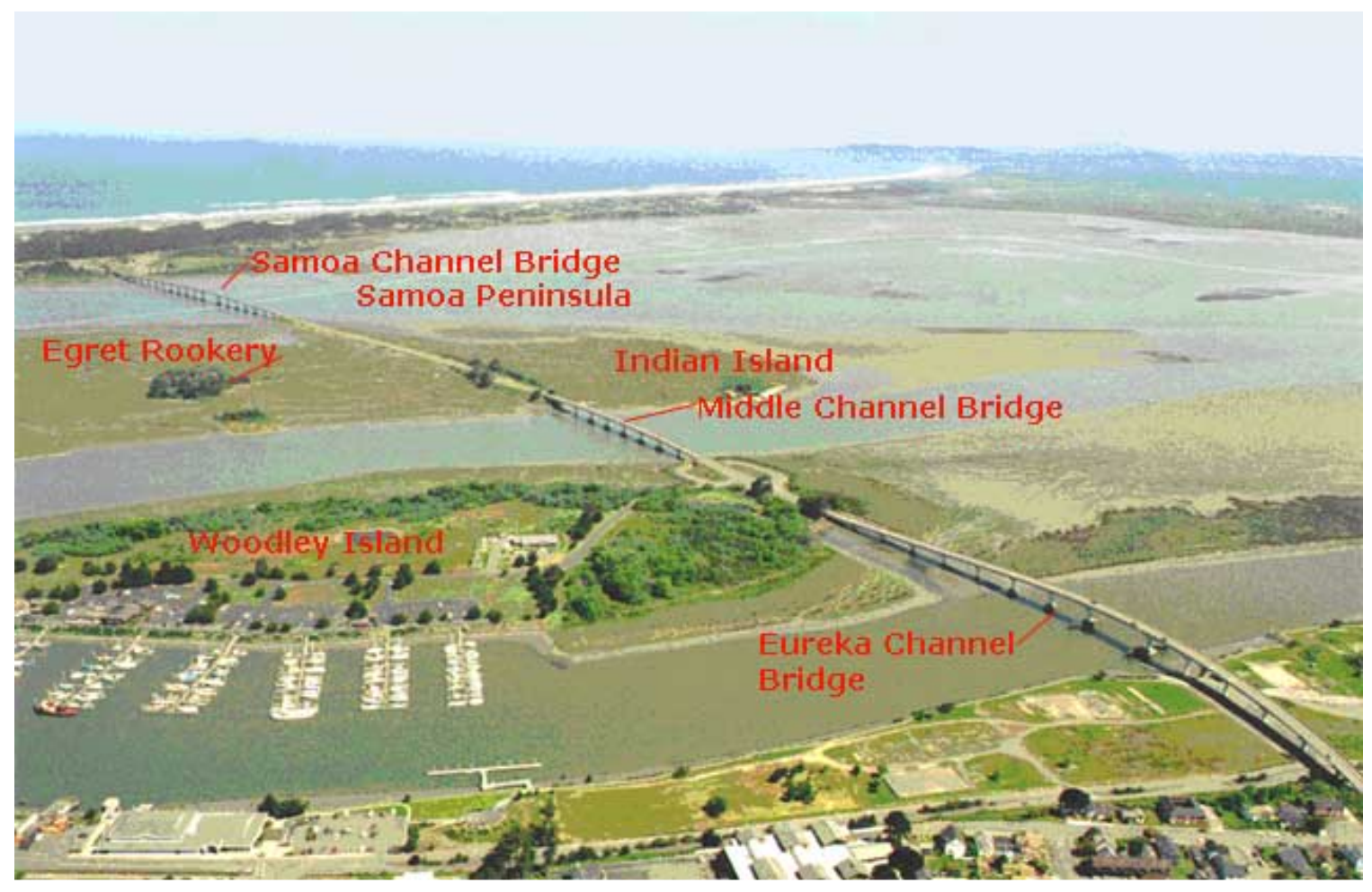

Figure 3. Humboldt Bay channel bridges (courtesy of Caltrans)

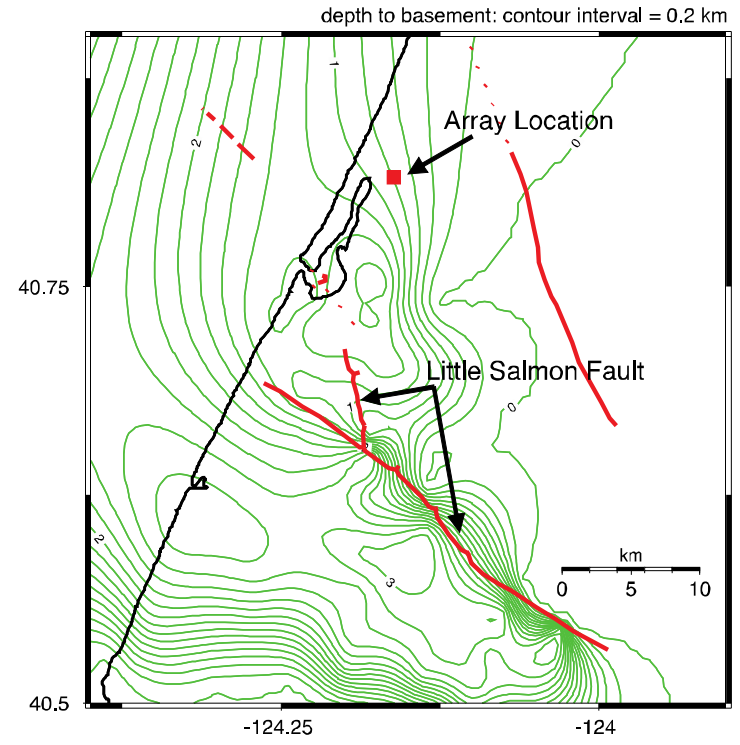

Figure 4. Map of the basin depth. Green contour lines show depth to the basement, and red lines indicate location of major faults. The geotechnical array location is shown by the red square. 

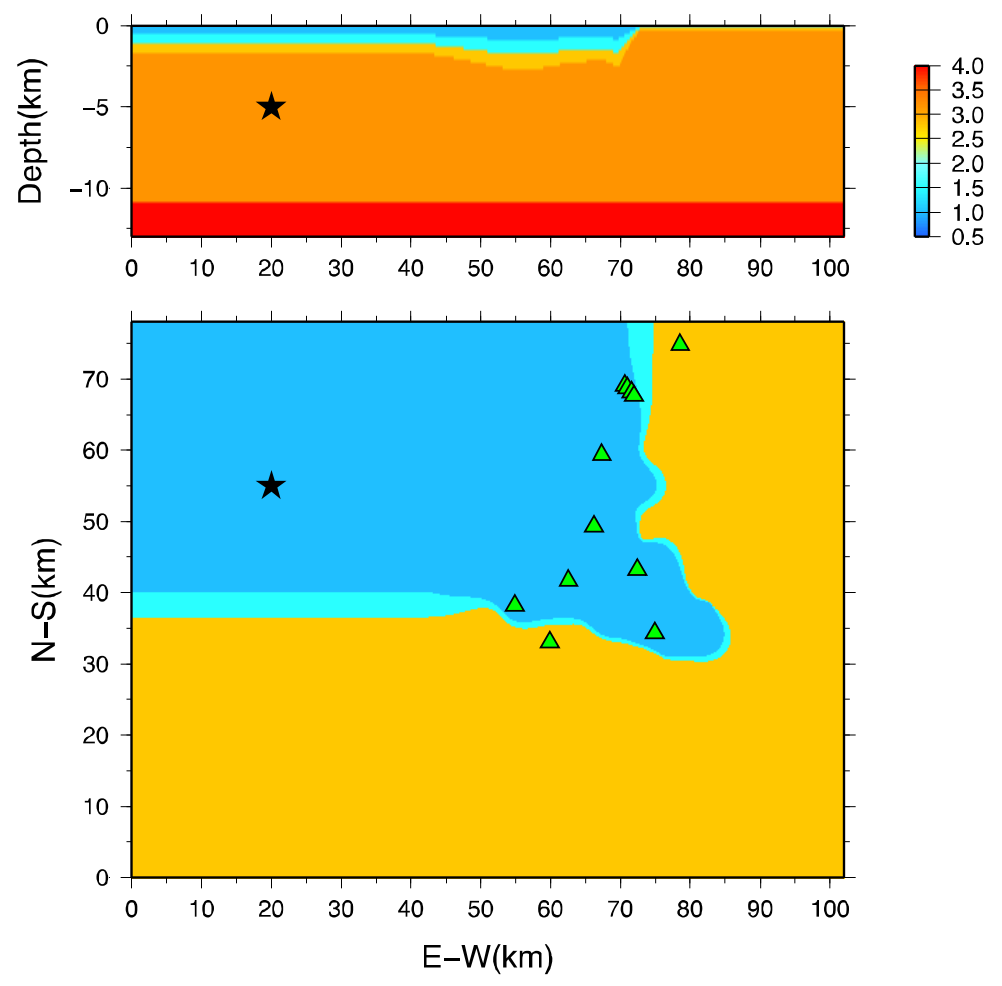

Figure 5. 3D velocity model. Top Panel: EW vertical section crossing the epicenter. Bottom Panel: Free surface velocity and stations location.

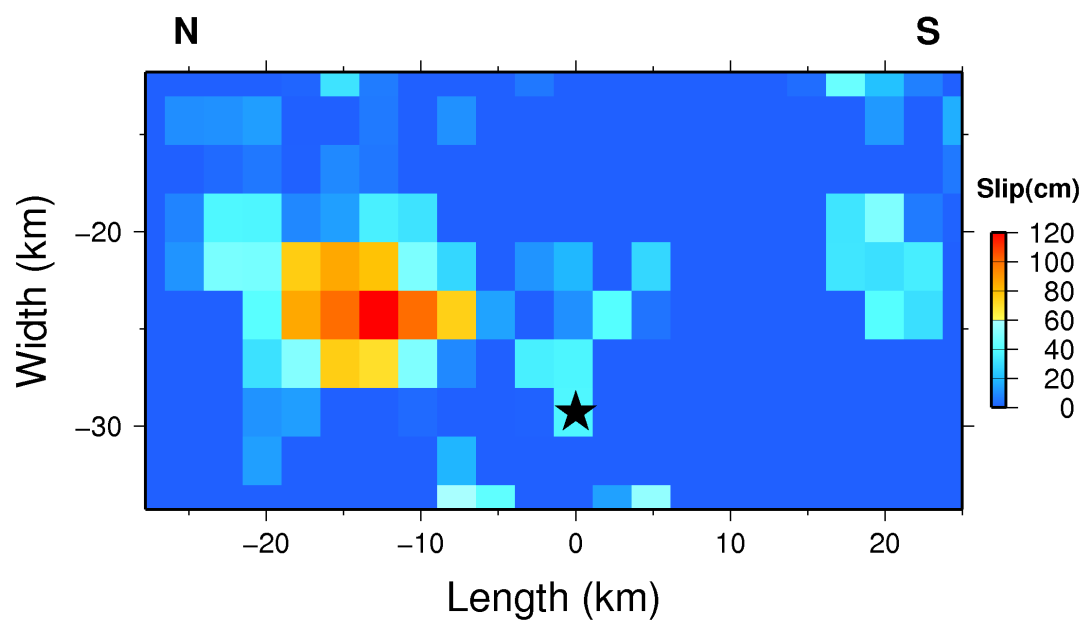

Figure 6. Kinematic slip model of the 2010 Ferndale earthquake used in the broad-band ground motion simulations. 

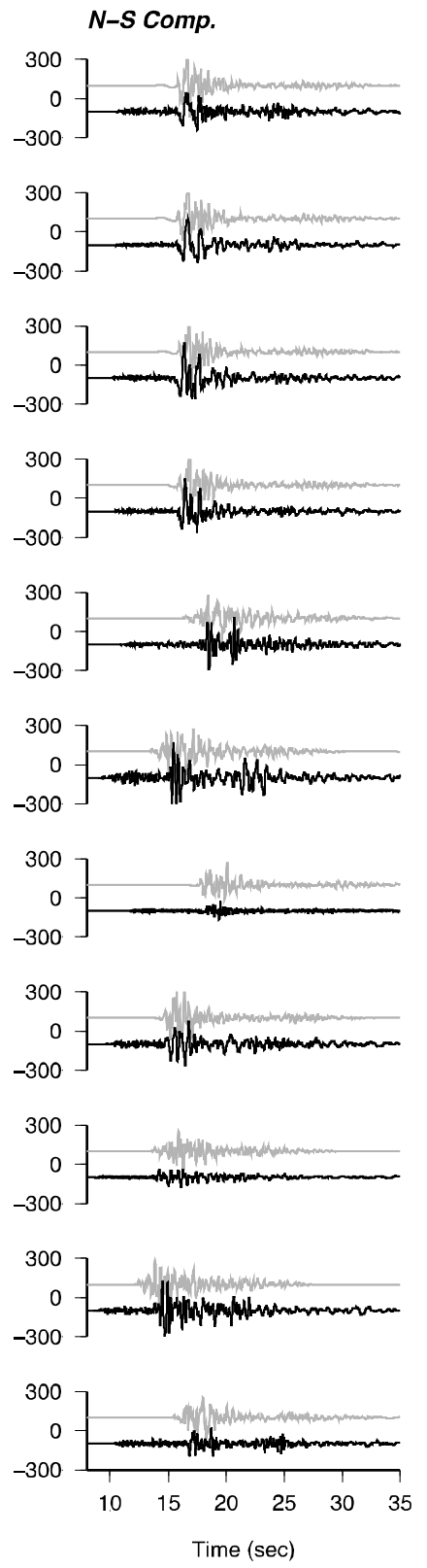
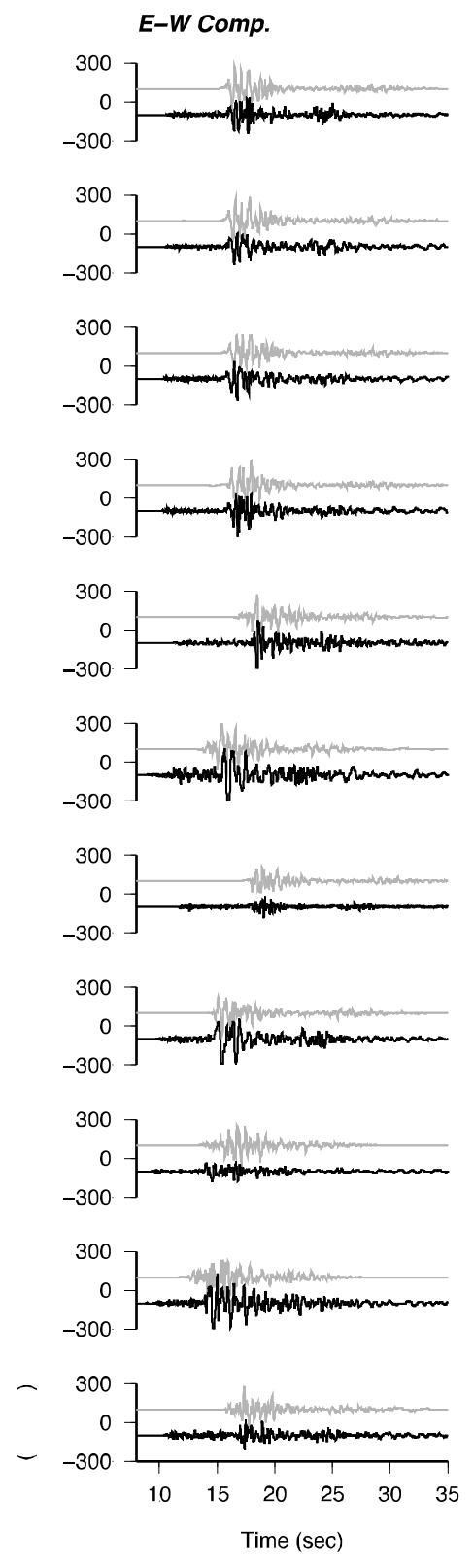
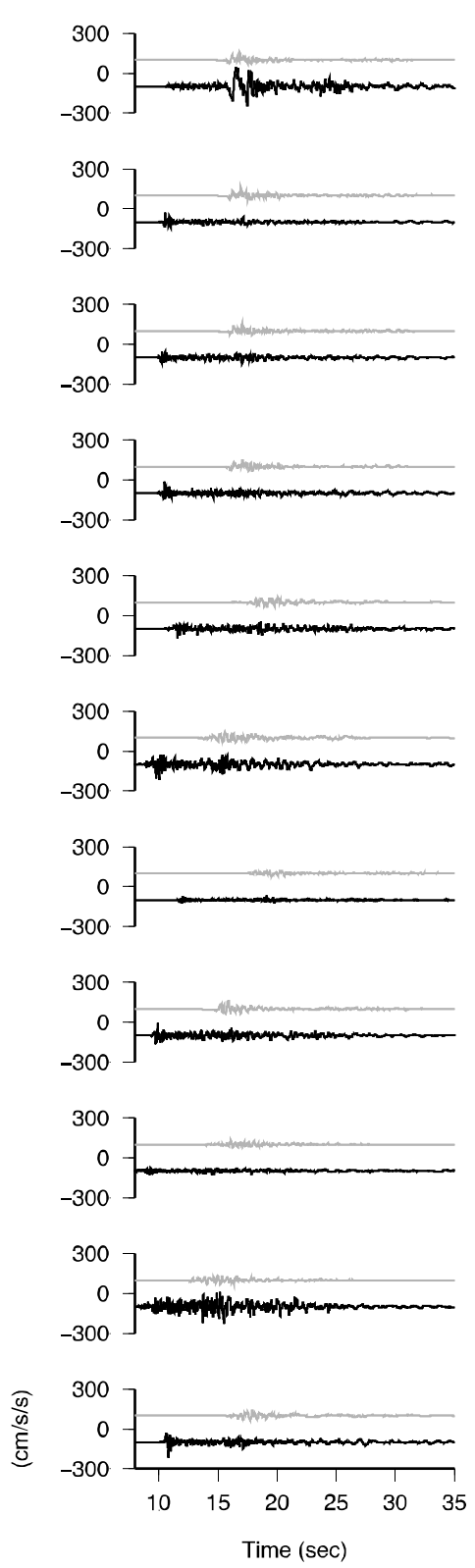

Figure 7a. Comparison of simulated (gray traces) and recorded (black traces) ground motion acceleration. 

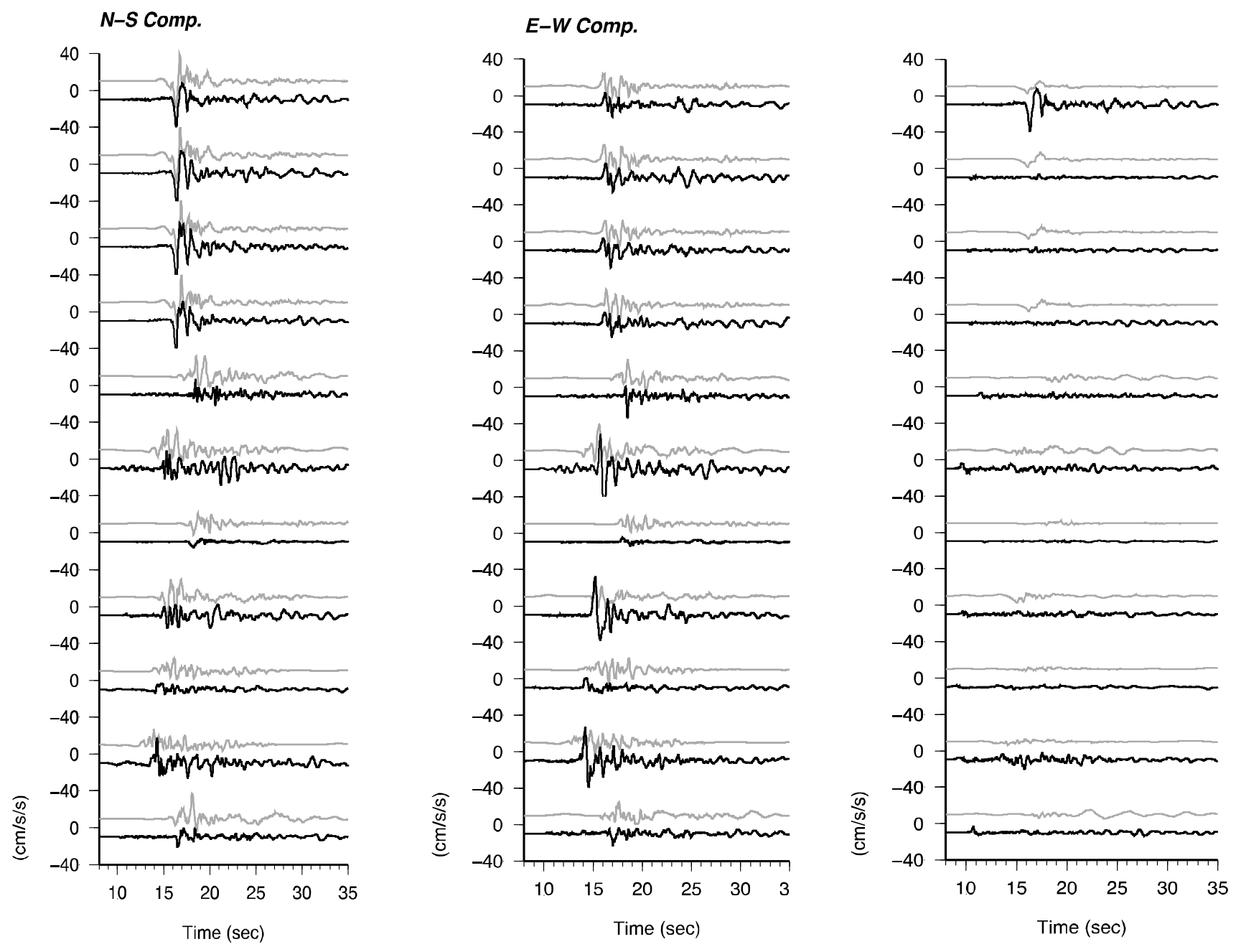

Figure 7b. Comparison of simulated (gray traces) and recorded (black traces) ground motion velocity. 

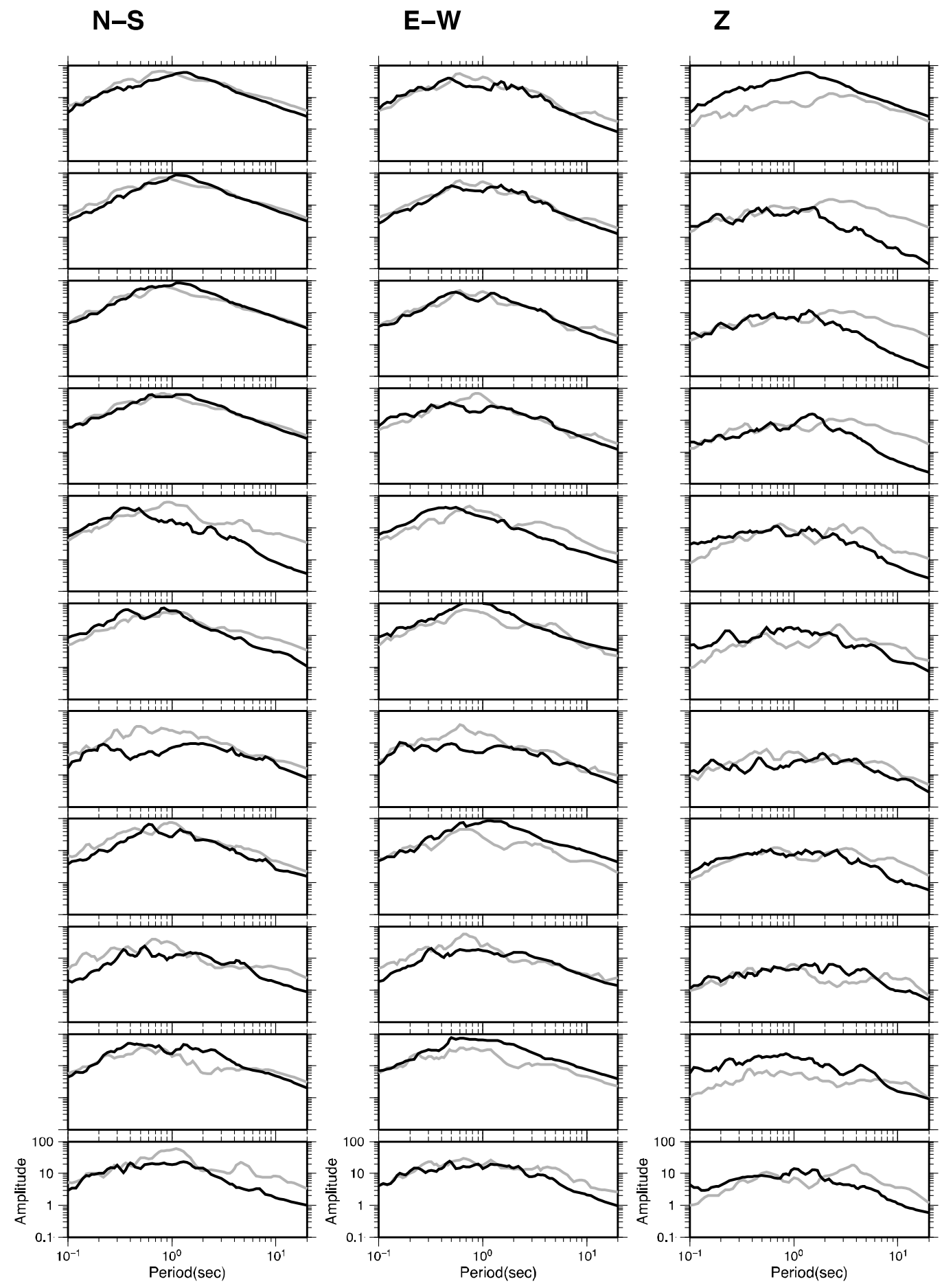

Figure 8. Comparison of simulated (gray traces) and recorded (black traces) ground motion acceleration response spectra. 

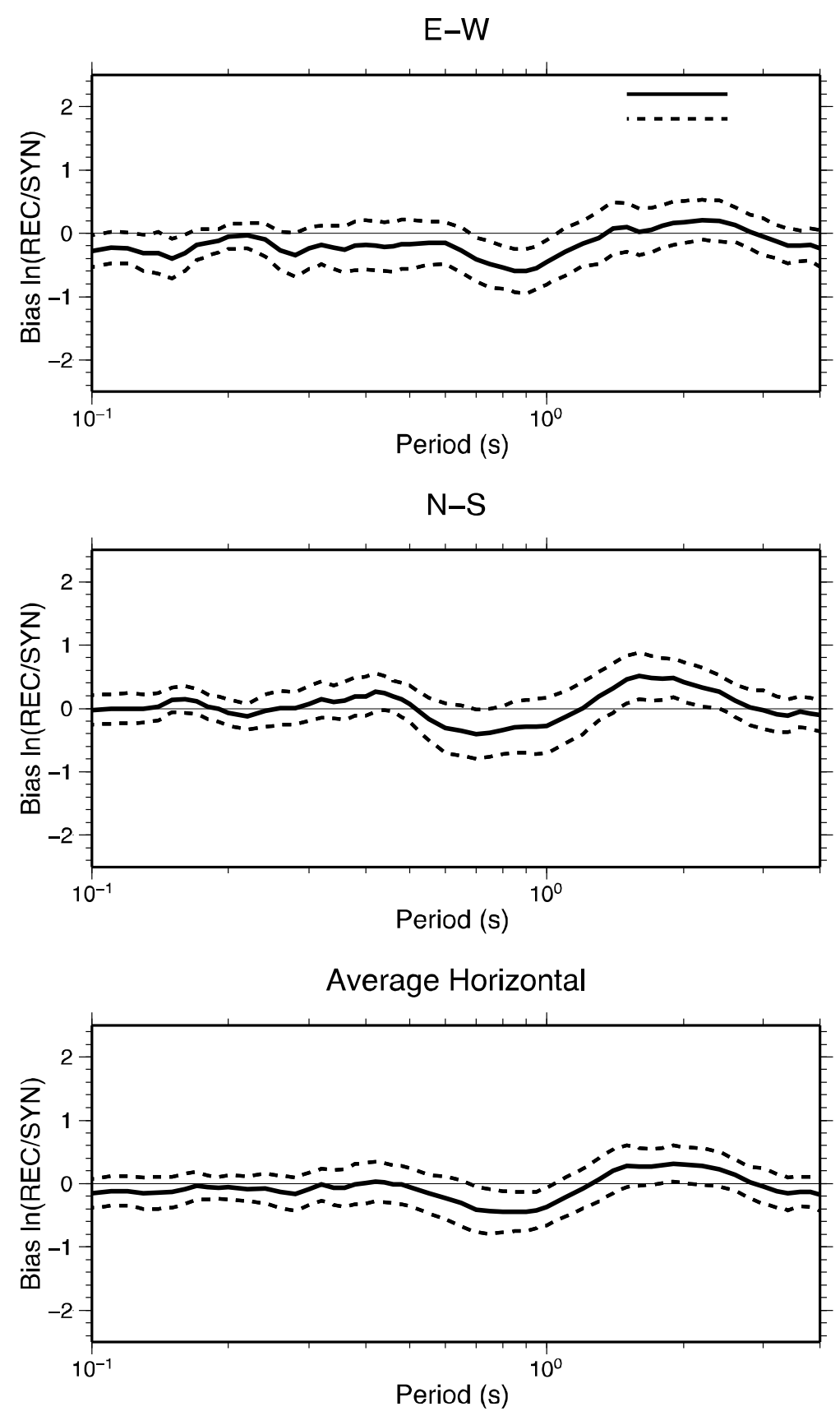

Figure 9. Model bias (heavy line) and standard error (area between dotted lines) for $5 \%$ damped spectral acceleration using 11 sites. Top panel shows the fault-parallel component, middle panel shows the fault-normal component, and bottom panel shows the average horizontal (geometric mean) component. 

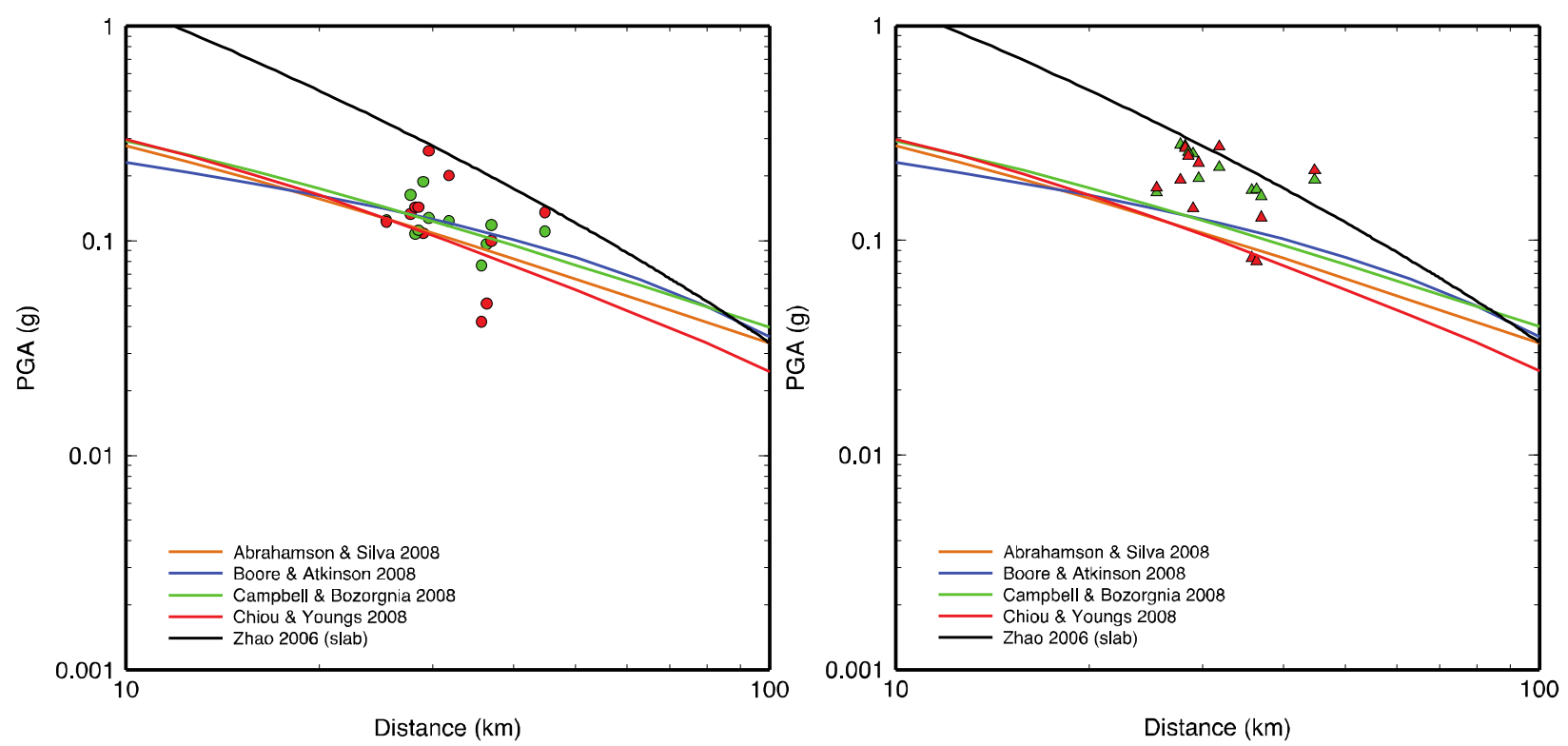

Figure 10. Comparison of simulated (green symbols) and recorded (red symbols) horizontal peak ground acceleration (left panel) and maximum horizontal acceleration (right panel) from the 2010 M6.5 Ferndale earthquake with predictions of the horizontal peak ground acceleration using different ground motion prediction equations.
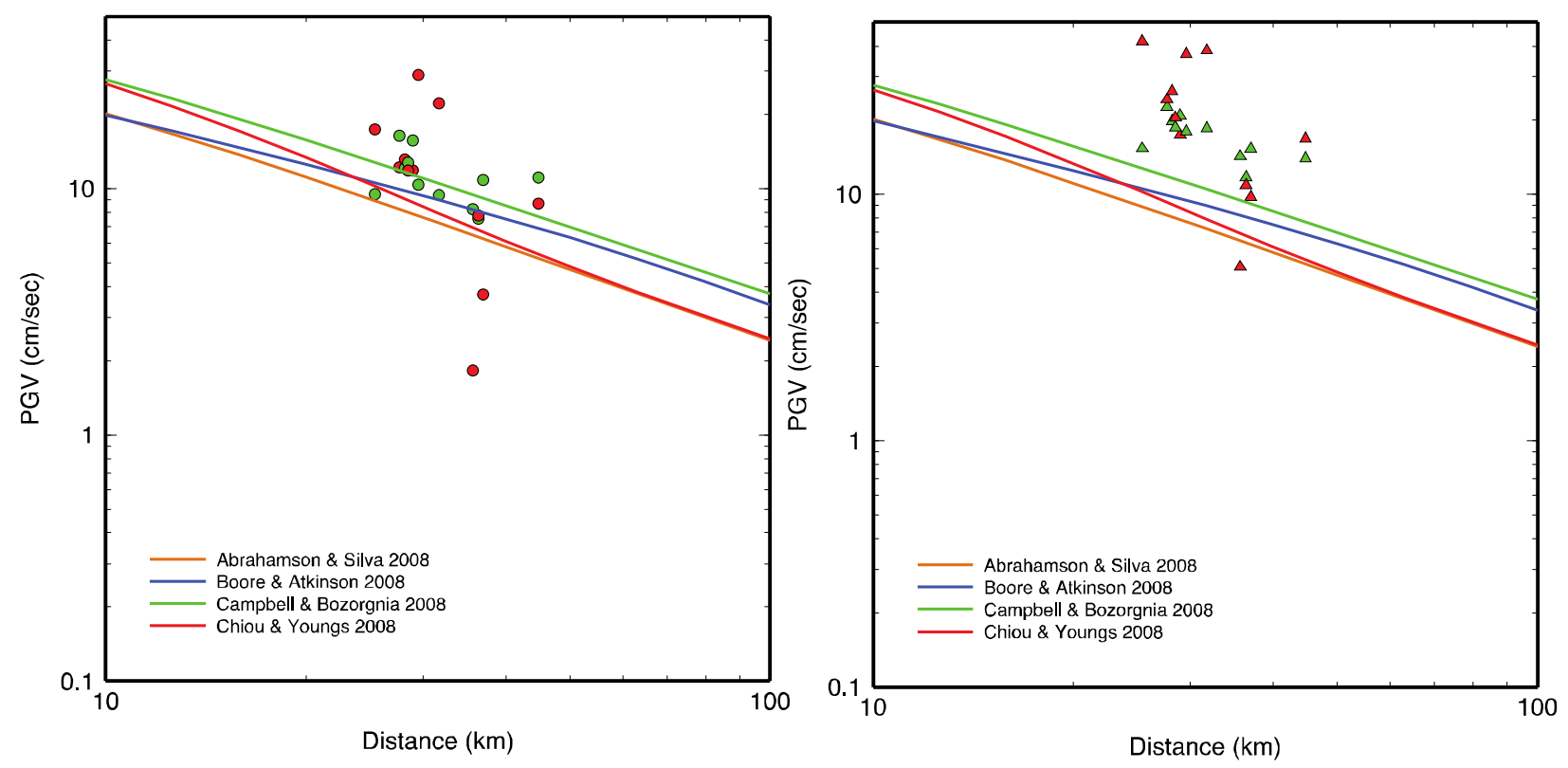

Figure 11. Comparison of simulated (green symbols) and recorded (red symbols) horizontal peak ground velocity (left panel) and maximum horizontal velocity (right panel) from the 2010 M6.5 Ferndale earthquake with predictions of the horizontal peak ground velocity using different ground motion prediction equations. 


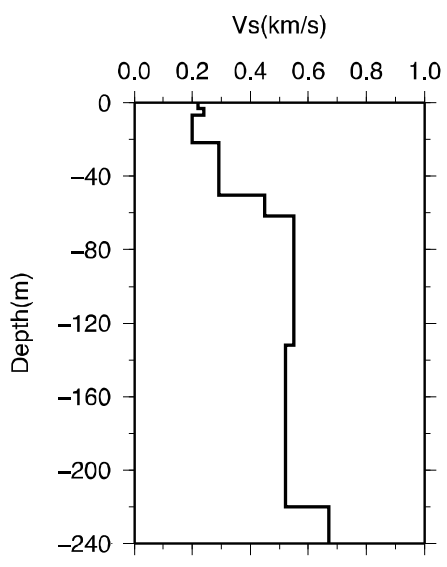

Figure 12. Shear-wave velocity profile used in the 1D non-linear analysis
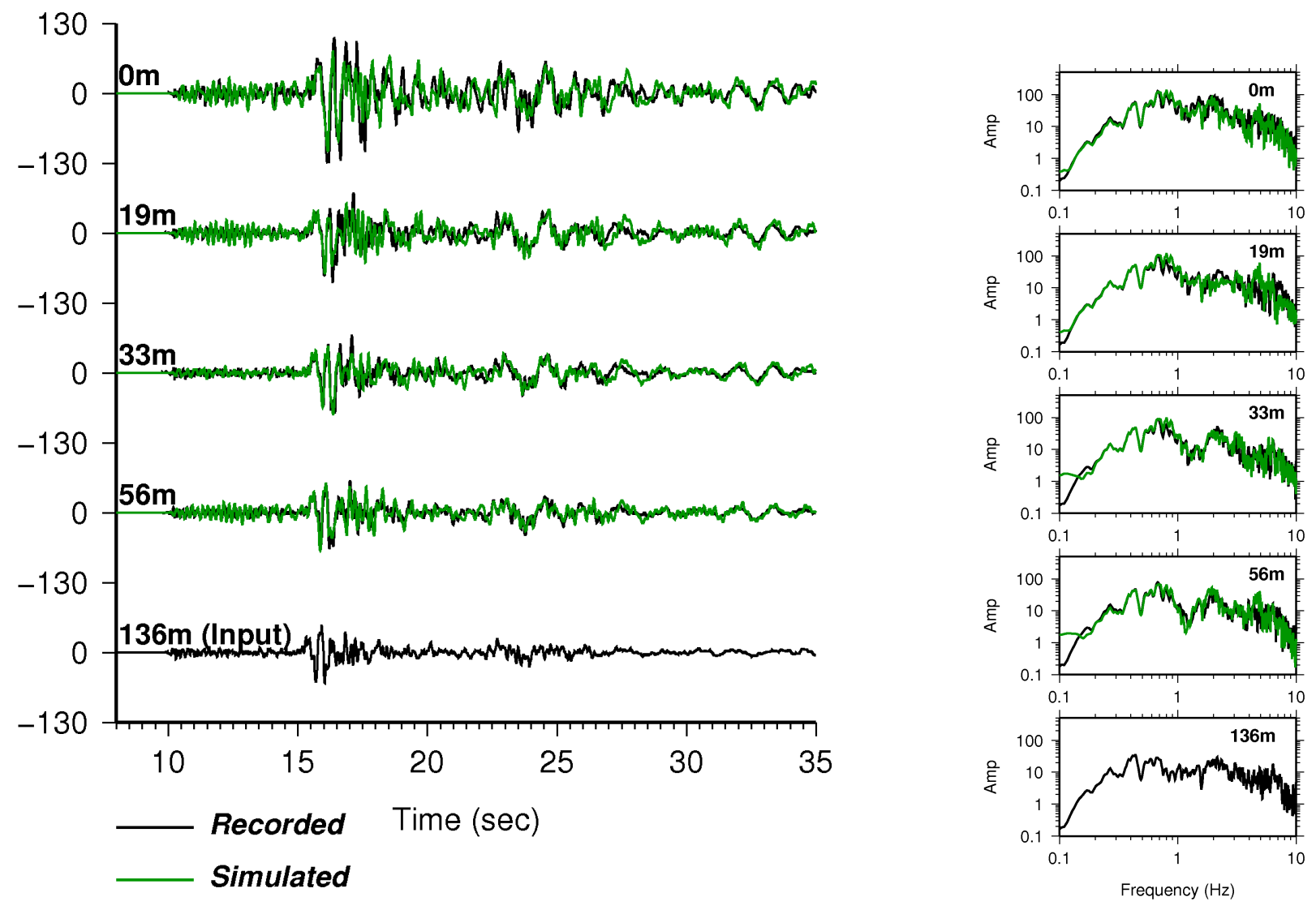

Figure 13. Comparison between recorded (black traces) and synthetic (green traces) E-W acceleration calculated at borehole stations using a fully non-linear technique. The input motion is applied at a depth of $136 \mathrm{~m}$. 

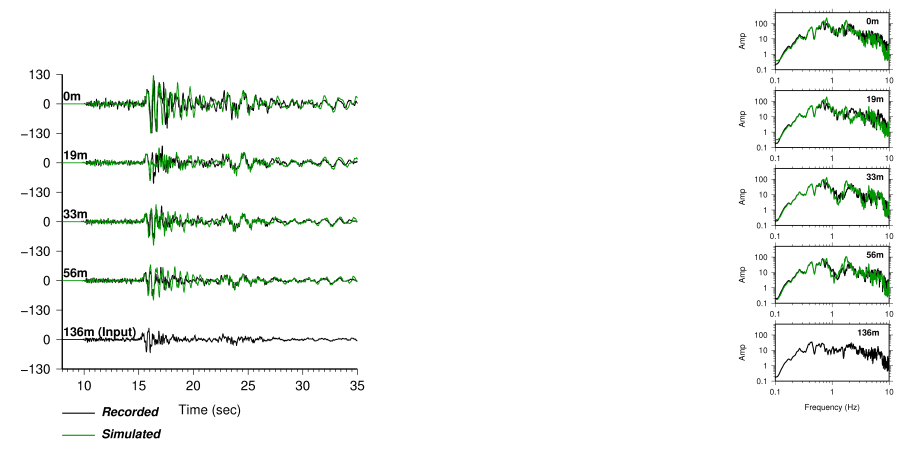

Figure 14. Comparison between recorded (black traces) and synthetic (green traces) E-W acceleration calculated at borehole stations using an equivalent linear technique. The input motion is applied at a depth of $136 \mathrm{~m}$.
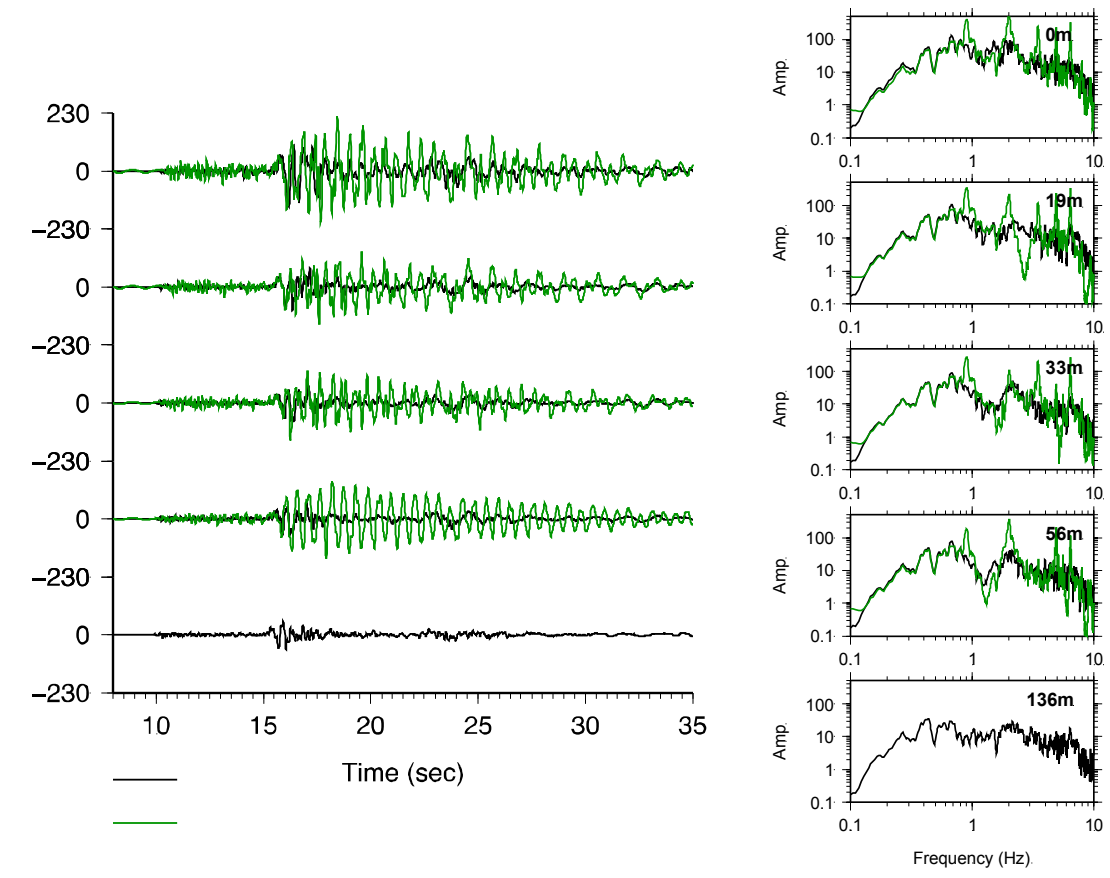

Figure 15. Comparison between recorded (black traces) and synthetic (green traces) acceleration calculated at borehole stations using linear soil response. 

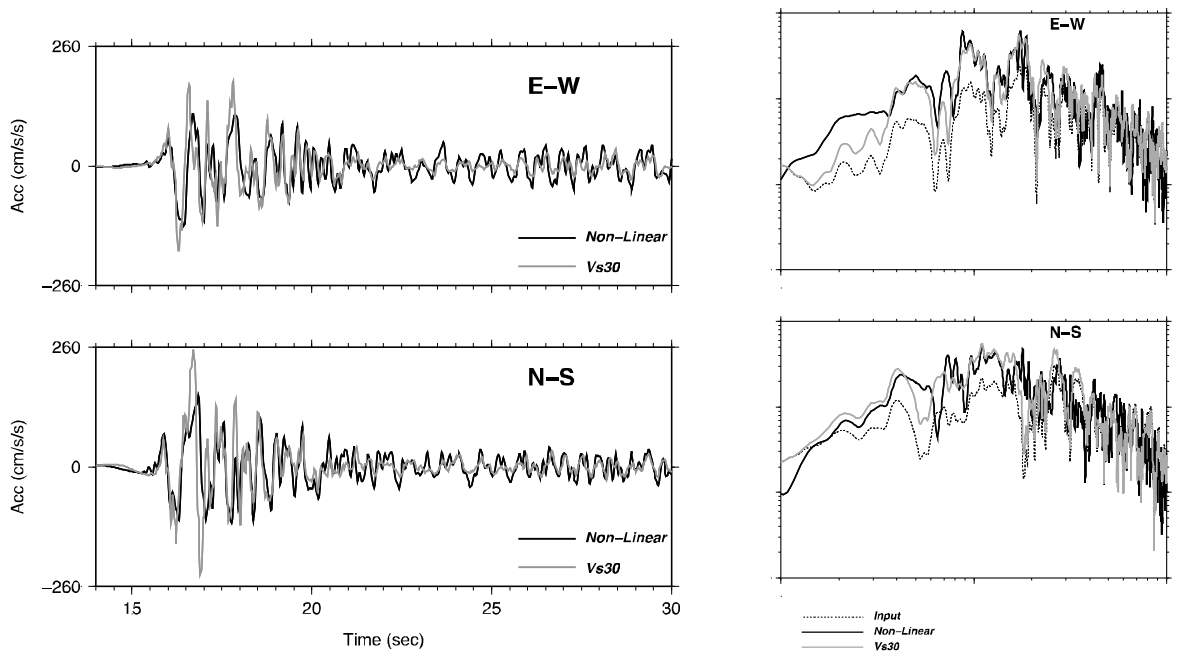

Figure 16. Performance of the Vs30 empirical site correction at the geotechnical array.

Comparison between synthetic acceleration time histories (left panels) and amplitude spectra (right panels) calculated at the free surface using 1D nonlinear site response (black traces) and empirical site correction (gray traces). Dotted line shows the amplitude spectrum of the input motion.
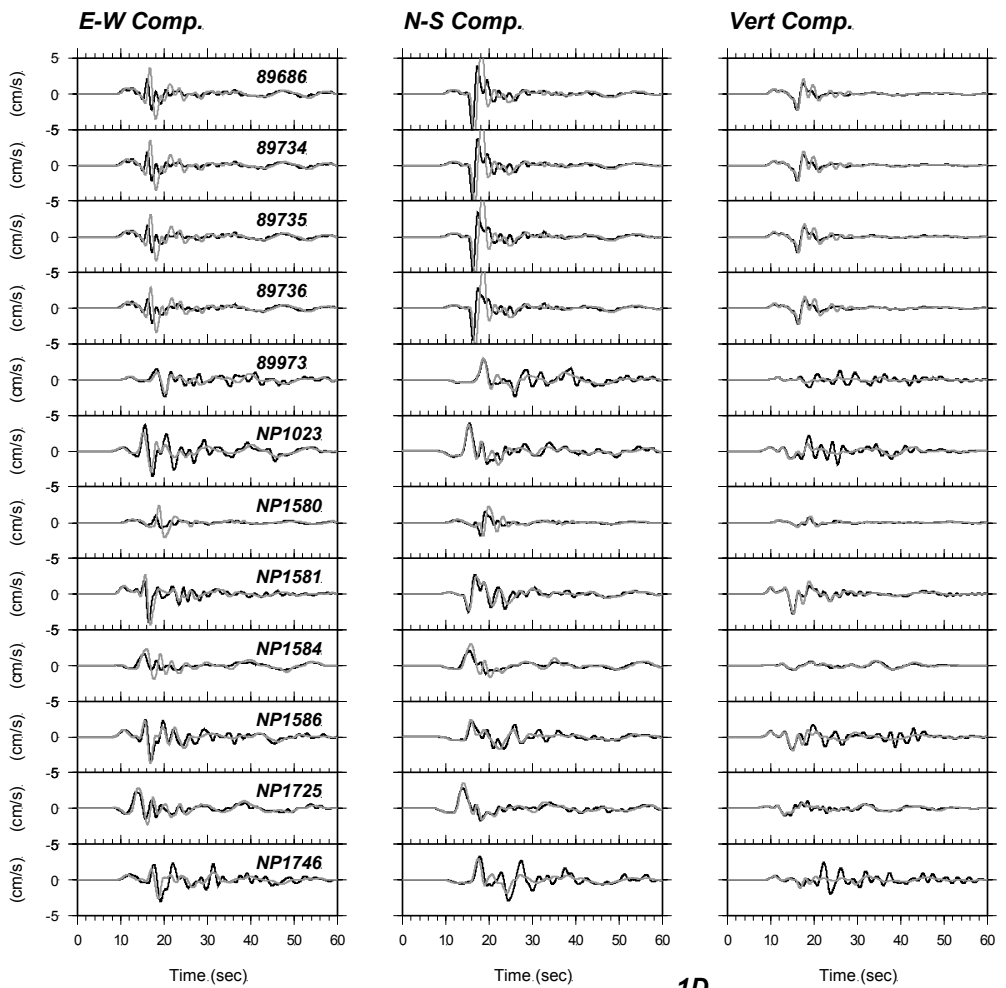

Figure 17. Synthetic velocity seismograms for the 2010 Ferndale earthquake computed with 1 local 1D and 3D basin model. The synthetic motion is band-pass filtered at 0.02-0.8 Hz. 